\title{
2p21 microdeletion syndrome without cystinuria
}

INSERM

\section{Source}

INSERM. (1999). Orphanet: an online rare disease and orphan drug data base. 2 p21

microdeletion syndrome without cystinuria. ORPHA:369881

$2 \mathrm{p} 21$ microdeletion syndrome without cystinuria is a rare partial autosomal monosomy characterized by weak fetal movements, severe infantile hypotonia and feeding difficulties that spontaneously improve with time, urogenital abnormalities (hypospadias or hypoplastic labia majora), global development delay, mild intellectual disability and facial dysmorphism (dolichocephaly, frontal bossing, bilateral ptosis, midface retrusion, open mouth with tented upper lip vermilion). Affected individuals have borderline elevated serum lactate but no cystinuria. 